\title{
As competências gerenciais nas instituições federais de educação superior
}

\author{
Managerial competencies in federal institutions of higher education
}

Aline Lucena Costa Pereira ${ }^{1}$

Anielson Barbosa da Silva²

\begin{abstract}
Resumo
O objetivo neste artigo é identificar as competências gerenciais nas Instituições Federais de Educação Superior (IFES). O referencial teórico aborda a evolução destas instituições, os desafios e possibilidades da ação do gestor público no contexto de mudanças e as competências gerenciais. Trata-se de uma pesquisa qualitativa, de natureza exploratória, que buscou captar a percepção de um grupo de gestores acerca das competências gerenciais de servidores técnicoadministrativos de três IFES do Nordeste brasileiro: Universidade Federal da Paraíba, UFPB; Universidade Federal de Pernambuco, UFPE; e a Universidade Federal do Rio Grande do Norte, UFRN. A amostra foi composta por vinte e um gestores públicos das áreas de recursos humanos, finanças, contabilidade e segurança que atuam nas referidas instituições. Na coleta de dados foi utilizado o método de focus group, cujas sessões foram gravadas em áudio, transcritas e cujos relatos foram analisados de forma compreensiva interpretativa. Os resultados da pesquisa permitiram ampliar a compreensão acerca das competências gerenciais no âmbito das IFES estudadas, bem como identificar quatro grupos de competências gerenciais: competências cognitivas, funcionais, comportamentais e políticas. Tais resultados podem fomentar discussões entre as IFES acerca do desenvolvimento das competências requeridas dos servidores, em especial gestores, em sua atuação profissional, o que pode auxiliar as IFES na implantação de diretrizes e no estabelecimento de uma política de desenvolvimento de gestores públicos que, ao mobilizarem competências, podem viabilizar o desenvolvimento de competências institucionais. Por meio do estudo exploratório, pretende-se realizar uma pesquisa quantitativa para avaliar o nível de domínio das competências, assim como o nível de encorajamento da instituição federal de ensino para o desenvolvimento das competências gerenciais.
\end{abstract}

Palavras-chave: Competências. Gestores públicos. Desenvolvimento de competências. Instituições federais de educação superior.

\footnotetext{
Artigo submetido em 08 de dezembro de 2010 e aceito para publicação em 01 de abril de 2010.

${ }^{1}$ Mestre em administração pela Universidade Federal da Paraíba/UFPB; Pró-reitoria de gestão de pessoas/PROGEP da Universidade Federal da Paraíba/UFPB. Endereço: Pró-reitoria de gestão de pessoas, Prédio da reitoria, Campus universitário/UFPB, CEP 58059900, João Pessoa, PB, Brasil. E-mail: alinelucenapsi@yahoo.com.br

2 Doutor em engenharia de produção pela Universidade Federal de Santa Catarina/UFSC; Professor do programa de pós-graduação em administração/PPGA e do departamento de administração da Universidade Federal da Paraíba/UFPB; Coordenador do núcleo de estudos em aprendizagem e competências (NAC). Endereço: Centro de ciências sociais aplicadas/CCSA, Programa de pósgraduação em administração/ PPGA, Campus universitário/UFPB, CEP 58059-900, João Pessoa, PB, Brasil. E-mail: anielson@uol.com.br
} 


\begin{abstract}
The aim of this article is to identify the managerial competencies in FIHE (Federal Institutions of Higher Education). The theoretical framework focuses on the evolution of FIHE, the challenges facing public managers and possible actions in a changing context and managerial competencies. This is a qualitative and exploratory study that sought to raise the perception of a group of managers concerning the managerial competenciesof technical and administrative servers for three FIHE in the northeast of Brazil: the Federal University of Paraíba (UFPB), the Federal University of Pernambuco (UFPE) and the Federal University of Rio Grande do Norte (UFRN). The sample included twenty-one public managers in the areas of human resources, finance, accounting and security who work at these institutions. The data collection method was the focus group, whose sessions were audio recorded and transcribed. The reports were analyzed in a comprehensive interpretation. The research findings advance the understanding of managerial competencies within the FIHE under study, and enabled the identification of four groups of managerial competencies:cognitive, functional, behavioral and political. These results may encourage discussions among FIHE concerning the development of the skills required of servers, particularly managers, in their professional practice, which can assist in the implementation of guidelines for FIHE and establish a development policy for public managers to mobilize competencies and enable the development of institutional skills. From the exploratory study, we intend to conduct a quantitative survey to assess the level of the domain of competenciesas well as the encouragement level of these Federal Institutions of Higher Education for the development of managerial competencies.
\end{abstract}

Keywords: Competencies. Public managers. Development of competencies. Federal institutions of higher education.

\title{
Introdução
}

Pessoas e organizações estão inseridas em um contexto permeado pela complexidade. Logo, é necessária a formação e o desenvolvimento de competências como saberes múltiplos (LE BOTERF, 2003) que possibilitem uma melhor atuação no contexto de trabalho. Os gestores desempenham um papel fundamental neste processo, e a mobilização de suas competências gerenciais se configura como um elo na transposição das competências individuais para as coletivas, o que pode favorecer o desenvolvimento das competências institucionais.

As Instituições Federais de Educação Superior (IFES) passaram a atuar em um cenário de mudanças que demandam a adequação da gestão de pessoas no serviço público a partir da institucionalização da lei 11.091/2005, que definiu o Plano de Carreira dos Cargos Técnico-Administrativos em Educação (PCCTAE) nas IFES, regulamentada pelos decretos 5.284/2006 e 5.285/2006. Além disso, o decreto 5.707/2006 instituiu a Política Nacional de Desenvolvimento de Pessoal (PNDP). Aprofundar este tema, especificamente o das competências gerenciais no contexto das IFES, pode contribuir para a implementação das diretrizes do PNDP. Uma dessas diretrizes indicadas no seu art. $1^{\circ}$, inciso III, destaca a necessidade de "adequação das competências requeridas dos servidores aos objetivos das instituições, tendo como referência o plano plurianual".

Alguns teóricos brasileiros, como Dutra (2004), propõem que diferentes contextos e atividades profissionais demandam categorias específicas de competências. Por sua vez, Amaral (2006) relaciona algumas características esperadas dos gestores públicos em face da utilização do modelo de competências, entre as quais estariam, além do aumento da responsabilidade, saber lidar com a incerteza, correr riscos, aprender coletivamente, questionar-se, bem como modificar sua percepção acerca dos benefícios trazidos pela experiência. Outro aspecto relevante é destacado por Fleury e Fleury (2001), ao reforçarem que a identificação das competências individuais deve estar alinhada aos objetivos da organização, tecendo uma conexão entre a estratégia e a gestão de pessoas. 
A literatura apresenta estudos que evidenciam modificações nos modelos administrativos do Estado, inovando o design na gestão de pessoas e no perfil do servidor (BRASIL, 1995; ENAP, 2009; NOGUEIRA, 2005; SOUZA, 2002). É válido destacar que o governo abrange serviços prioritários (educação, saúde, transporte e segurança) para a sociedade (NEWCOMER, 1999; SOUZA, 2002), além da sua relevância como empregador (BORGES, 2004; NOGUEIRA, 2005). Portanto, a atuação dos gestores públicos impacta diretamente na agilidade, eficiência e eficácia das atividades prestadas pelo Estado, o que reforça a necessidade de a própria administração pública conhecer melhor as competências de seus gestores no contexto da ação profissional.

Neste artigo objetiva-se identificar as competências dos gestores públicos das IFES para propor alternativas que possibilitem sua formação e desenvolvimento, colaborando para a ampliação de uma política de fomento para a área de gestão de pessoas no serviço público federal, ao ampliar a discussão acerca da gestão por competência no contexto destes órgãos.

\section{Referencial Teórico}

A gestão de pessoas na administração pública federal brasileira confunde-se com a evolução do processo histórico do país. O surgimento, desenvolvimento e expansão das Instituições Federais de Ensino Superior (IFES) são concomitantes a acontecimentos históricos, culturais e políticos que influenciaram sua estrutura e valores. Percebe-se que esta conjuntura histórica repercutiu na sua organização e nas atuais políticas públicas de educação. Mediante análise da evolução das IFES, foi possível identificar seis períodos no percurso pelo qual estas instituições passaram, de acordo com características comuns e fatos relevantes, quer sejam a criação de universidades, órgãos públicos ou movimentos sociais e políticos. Descrevem-se, a seguir, de maneira sucinta as origens das instituições de ensino no Brasil. O Quadro 1 sintetiza a análise histórica, apresentando o período e sua caracterização e eventos relevantes.

\section{Quadro 1}

\section{Evolução das IFES no Brasil}

\begin{tabular}{|l|l|l|}
\hline \multicolumn{1}{|c|}{ Período } & \multicolumn{1}{|c|}{ Fonte } & \multicolumn{1}{c|}{ Eventos Relevantes } \\
\hline $\begin{array}{l}\text { Período colonial } \\
\text { (1808 a 1889) }\end{array}$ & $\begin{array}{l}\text { Andrade (2008) } \\
\text { Fávero }(2000,2006)\end{array}$ & $\begin{array}{l}\text { Ensino superior era privilégio das elites; } \\
\text { primeiras faculdades: direito e medicina (BA, RJ, PE, } \\
\text { RS) }\end{array}$ \\
\hline $\begin{array}{l}\text { Anos 1930 a 1970 } \\
\text { (1936 a 1978) }\end{array}$ & $\begin{array}{l}\text { Andrade (2008) } \\
\text { Fávero (2000, 2006) }\end{array}$ & $\begin{array}{l}\text { Federalização dos institutos de ensino no Brasil; } \\
\text { Decreto-lei no 200/67 (planejamento, coordenação } \\
\text { descentralização, delegação de competência e } \\
\text { controle) }\end{array}$ \\
\hline Anos 1980 & $\begin{array}{l}\text { Andrade (2008) } \\
\text { Fávero (2000, 2006) }\end{array}$ & $\begin{array}{l}\text { Redemocratização política (eleições diretas, } \\
\text { Constituição de 1988); } \\
\text { políticas públicas (educação gratuita e de qualidade) }\end{array}$ \\
\hline
\end{tabular}




\begin{tabular}{|c|c|c|}
\hline Anos 1990 a 2000 & $\begin{array}{l}\text { Borges (2004) } \\
\text { ENAP (2009) } \\
\text { Nogueira (2005) }\end{array}$ & $\begin{array}{l}\text { Regime Jurídico Único (RJU); } \\
\text { privatizações e demissões voluntárias }\end{array}$ \\
\hline Anos 2000 & $\begin{array}{l}\text { ENAP (2009) } \\
\text { Nogueira (2005) }\end{array}$ & $\begin{array}{l}\text { Contratações de técnicos e docentes; } \\
\text { nova fase de expansão das universidades federais }\end{array}$ \\
\hline $\begin{array}{l}\text { Período Atual } \\
\text { REUNI }\end{array}$ & $\begin{array}{l}\text { ENAP (2009) } \\
\text { SINAES (2007) }\end{array}$ & $\begin{array}{l}\text { Interiorização do ensino superior; } \\
\text { criação de novos cursos de graduação e pós- } \\
\text { graduação; investimento na melhoria da } \\
\text { infraestrutura e contratação de novos servidores } \\
\text { técnicos e docentes }\end{array}$ \\
\hline
\end{tabular}

Fonte: Elaborado pelos autores, 2010.

Compreende-se que estas transformações históricas, sociais e políticas estão alinhadas a mudanças mais amplas na esfera do trabalho. O ambiente da ação gerencial no período atual exige maior profissionalismo no gerenciamento das políticas de gestão de pessoas no serviço público. Os marcos legais institucionalizados pelo governo federal suscitaram mudanças nas políticas e estratégias de gestão de pessoas e favoreceram a introdução da lógica das competências como uma abordagem capaz de garantir um maior profissionalismo nas IFES, configurando o gestor como um elo nessa transposição das competências individuais, ao nível coletivo e organizacional (ENAP, 2009).

\section{A ação do gestor público: desafios e possibilidades}

A administração pública reflete o contexto de mudanças que fomenta reflexões sobre a forma de pensar a performance do governo (ORMOND e LÖFFLER, 1999). Esse desempenho é questionado na medida em que se abre um espaço de discussão com a sociedade, provocando satisfação/insatisfação com a administração pública.

Estado, organizações e pessoas estão inter-relacionados e mais conectados, uma vez que a tecnologia da informação e a internet ampliam o escopo dos processos de trabalho, mas não substituem a ação humana, que é responsável pela interpretação das informações. Tais alterações exigem capacidades gerenciais maiores para lidar com este novo contexto social (ENAP, 2009; PENENGO, 1997; ZARIFIAN, 2003).

O aumento da complexidade do trabalho adicionado a uma maior exigência com a eficiência do governo fomentou o debate acerca da gerência pública - ou New Public Management (NPM) - e discute as possibilidades e os desafios para as organizações públicas. Ormond e Löffler (1999) destacam que cada país deve observar suas especificidades e não há um modelo ideal ou prescritivo Estes autores, ao refletirem sobre um conceito para a gerência pública, salientam que "o debate ideológico realizado tem percebido a NPM como uma finalidade em si mesma, que define um estado desejável da administração pública em termos de estrutura, funcionamento e resultados" (ORMOND e LÖFFLER, 1999, p.87). E, para alcançar esse estado ideal, os gestores públicos percebem limites e possibilidades à sua atuação. O contexto deste estudo delimitase ao campo da gestão de pessoas. Busca-se, aqui, compreender como gestores aqueles servidores públicos que desenvolvem funções gerenciais, e que podem se situar em diferentes níveis hierárquicos na 
organização. O gestor público tem a possibilidade de construir um caminho seguro da situação presente a uma situação desejada. Assim, os gestores configuram-se como os principais agentes na condução das transformações dos processos de trabalho rumo à situação almejada e exercem um papel fundamental no processo de transposição das competências individuais (encontradas nos servidores) ao nível das organizacionais (associadas aos elementos da estratégia competitiva da organização: visão, missão, objetivos e metas), possibilitando a execução de responsabilidades e atribuições cada vez mais complexas.

Nessa configuração, uma possibilidade inicial consiste em observar os diversos papéis que os gestores desempenham e vê-los como personagens essenciais que podem auxiliar as organizações na gestão de pessoas em sua prática profissional. Ao executar estes papéis, sobretudo na convivência com os outros, necessitam de um atributo específico em sua ação, que é a de atuar como líder.

A liderança representa um papel crucial ao trabalho gerencial, constituindo um "processo de influência, geralmente de uma pessoa, por meio do qual um indivíduo ou grupo é orientado para o estabelecimento de metas" (BOWDITCH e BUONO, 2002, p. 118). Observam-se dois tipos de liderança: a transacional, caracterizada pela troca de favores, e a transformacional, baseada em ideias, metas e emoções. As características do líder transformacional envolvem fé nas pessoas, orientação por valores e busca do aprendizado, além da capacidade de lidar com a complexidade. Na medida em que os servidores se apropriam dos valores difundidos pelo gestor, internalizando-os, é atribuído um significado simbólico ao trabalho que sintoniza um estado de motivação (BITENCOURT e BARBOSA, 2004) e propicia um maior comprometimento.

A adaptabilidade ao contexto e o manejo dos problemas futuros constituem uma possibilidade discutida por Ormond e Löffler (1999). E como os gestores podem viabilizá-la? A resposta caminha em direção à abertura da organização aos processos de aprendizagem organizacional e das competências no trabalho. Ao perceber a necessidade de fornecer respostas dinâmicas às demandas, a organização e seus membros necessitam aprender. Assim, sua estrutura é visualizada como um sistema aberto, em homeostase, mantendo trocas constantes com o meio (SENGE, 1990). O processo de aprendizagem também é mediado pelo contexto e pela experiência vivida (McGILL e BROCKBANK, 2004; SILVA, 2009). Portanto, ele ocorre na ação, no cotidiano e, especialmente, nas trocas sociais. Logo, as pessoas também "aprendem por meio das experiências vividas" (SILVA, 2009 p. 189).

A revitalização da cultura configura-se como um componente valioso, ajustando-se às exigências do setor público na busca por profissionais mais qualificados e comprometidos. Megginson, Mosley e Pietri (1998, p. 430) afirmam ainda que "outra cilada da ênfase da cultura organizacional é ela se tornar rígida e não mudar, quando o ambiente externo muda. Um problema relacionado é ter diretrizes impossíveis de realizar". Assim, na interação social, os valores e percepções são compartilhados no cotidiano da organização e constituem um fenômeno que poderá favorecer ou dificultar a implantação da gestão em um órgão público.

Outro elemento que poderá auxiliar os gestores a compor o seu trabalho com êxito fundamenta-se na elaboração de um modelo próprio de desenvolvimento, o que se constitui em algo bastante complexo e envolve múltiplos aspectos. A configuração pensada deve considerar o sistema sociopolítico do país, as bases legais que sustentam o setor público e a flexibilidade na estrutura, pois existem diferentes estágios de nivelamento em cada órgão. Temas como cultura, ética, responsabilidade e o envolvimento da sociedade na elaboração desta proposta são bem-vindos.

No que se refere aos desafios colocados aos gestores, um dos principais representa a gestão de pessoas alinhadas a competências. A base legal existe (diretrizes da Lei 11.091/2005); no entanto, a dificuldade consiste na sua implantação. Autores como Bitencourt e Apple (2005) fazem uma reflexão crítica sobre as 
dificuldades da gestão por competências, entre as quais se destacam: a) manutenção de uma perspectiva estática em detrimento da dinâmica; b) falta de planejamento para as necessidades futuras em relação a novas competências que poderão ser exigidas, considerando que o trabalho encontra-se mais complexo; c) imediatismo em relação ao sucesso, sem comprometimento com o processo de aprendizagem e reflexão sobre a atividade de insucesso; d) vinculação à remuneração, o que pode ocasionar dificuldades com a justiça do trabalho. Dutra (2004) acredita que, com o desenvolvimento da gestão por competência, as atuais dificuldades sejam gradativamente superadas.

Outra dificuldade envolve o desenvolvimento de um perfil proativo nos servidores. Os gestores trabalham administrando estruturas compostas por pessoas e processos, delegam atribuições e responsabilidades, mas nem todos mostram-se aptos a assumir demandas atuais e prever novas. O desenvolvimento de modelos que integrem a estratégia das IFES à gestão por competências, enfatizando as dificuldades que precisam ser aperfeiçoadas, pode ser uma alternativa viável. A adequação ao modelo de gestão por competência indica que as pessoas agregam valor às organizações, modernizando práticas e processos. As pessoas podem ser percebidas como essenciais à sobrevivência organizacional pela geração e compartilhamento do conhecimento, oxigenando e inovando, com ideias distintas, práticas e processos já existentes (SILVA, 2009).

Estudos como o de Ormond e Löffler (1999) destacam desafios que retratam a realidade das IFES, como as limitações fiscais. A operacionalização do trabalho no contexto público depende de autorizações orçamentárias vinculadas a processos legais. Isso ocasiona dificuldades relacionadas à compra de materiais, equipamentos, quantidade de recursos disponíveis para a capacitação, saúde, ou, ainda, passagens e diárias para os servidores que devem viajar a serviço, entre outras demandas. Enfim, enquanto o orçamento não é aprovado, muitos setores ficam sem um funcionamento adequado. Outros autores, como Ring e Perry (1985), também afirmam que a organização pública tem seu ambiente sujeito mais fortemente a legislações e normas.

Outra dificuldade apontada pelos autores Ormond e Löffler (1999) refere-se a maiores demandas sociais. No contexto das universidades, observa-se uma crescente demanda não somente com a criação de novos cursos de formação (graduação e pós-graduação), mas também nos serviços oferecidos à comunidade pelos projetos de extensão desses cursos, principalmente na área da saúde (Medicina, Odontologia, Fisioterapia, Nutrição, Psicologia). Esse aumento da demanda é agravado pelo envelhecimento da população e pelas condições socioeconômicas, o que demanda a oferta de serviços gratuitos e com qualidade. Esses aspectos colocam as universidades como uma prioridade nesta procura. Atualmente, algumas propostas têm sido realizadas visando a adequar uma maior oferta a essa crescente demanda por cursos e serviços oferecidos pelas IFES, a exemplo do Programa de Apoio a Planos de Reestruturação e Expansão das Universidades Brasileiras (REUNI).

O comportamento ético também pode ser um entrave ao trabalho dos gestores. Diversos escândalos envolvem organizações públicas, normalmente relacionadas ao desvio de verbas e não observância da legislação. Isso representa uma limitação, fazendo-se necessário institucionalizar e difundir novos valores organizacionais que sejam incorporados por seus membros para melhorar a imagem dos gestores públicos. A interferência da mídia nas decisões políticas também é um fator limitante (RING e PERRY, 1985), na medida em que interfere em decisões e direciona a formação da opinião pública, provocando, em alguns casos, decisões nem sempre adequadas à gestão. Esses aspectos que restringem e dificultam a gestão no setor público, influenciando fortemente o comportamento dos gestores, podem ser resumidos no Quadro 2. 
Quadro 2

Possibilidades e desafios para os gestores públicos

\begin{tabular}{|l|l|}
\hline \multicolumn{1}{|c|}{ POSSIBILIDADES } & \multicolumn{1}{c|}{ DESAFIOS } \\
\hline $\begin{array}{l}\text { Adaptação ao contexto e manejo dos problemas } \\
\text { futuros }\end{array}$ & Demanda social crescente \\
\hline Aprendizagem Organizacional & $\begin{array}{l}\text { Desenvolver atitudes adequadas } \\
\text { (perfil proativo e comportamentos éticos) }\end{array}$ \\
\hline Cultura organizacional flexível & Revitalizar a cultura organizacional \\
\hline Elaboração de modelo de desenvolvimento p/ IFES & Implantar a gestão por competências \\
\hline
\end{tabular}

Fonte: Elaborado pelos autores, 2010.

Os gestores representam os agentes determinantes na implantação de mudanças na gestão pública em geral e na gestão de pessoas em particular. Nesse processo, precisam desenvolver competências que os tornem agentes de transformação institucional que contribuem para o desenvolvimento da sociedade.

\section{Competências gerenciais}

A acomodação das organizações às mudanças vivenciadas na atualidade exige uma nova concepção de profissionais capazes de lidar com as incertezas presentes no mundo do trabalho e direciona o enfoque para as competências gerenciais como alternativa promissora às constantes transições presentes neste contexto. A partir dos anos 1990, observa-se um aumento do trabalho informal, crescimento do setor de serviços e crise nas associações sindicais (ANTUNES, 2000; COSTA, 2005; HARVEY, 2000), modificando o contexto do trabalho. Assim, um maior foco é dado ao resultado, ao produto do trabalho, do que à forma como é produzido. Ao considerar este cenário, o conceito de competências constitui um suporte às novas demandas, pois destaca as situações imprevistas enfrentadas nas mudanças ocorridas no mundo do trabalho.

É no contexto da prática profissional, frente a uma situação profissional vivenciada, que se observa a incorporação do conceito de competência. Esta é demonstrada, qualificada e validada na ação do indivíduo (FLEURY e FLEURY, 2001). De acordo com Zarifian (2001, p. 72), "a competência é um entendimento prático de situações que se apoia em conhecimentos adquiridos e os transforma na medida em que aumenta a diversidade de situações". O indivíduo mobilizará os seus conhecimentos no contato com as situações do contexto profissional, modificando-os por meio de análise e compreensão dos fatos e pela reflexão posterior à ação. É necessário compreender a situação, seus elementos (materiais ou humanos), o objetivo da ação, suas implicações (julgamento e responsabilidade) e a interação com o outro (colega, cliente, gestor), estabelecendo um agir prático inteligente e empático que satisfaça aos aspectos objetivos (externos, do contexto) e subjetivos (percepções, emoções) envolvidos nesse agir. Isso é imprescindível em um contexto marcado pela incerteza e por imprevistos, acontecimentos não rotineiros, definidos por Zarifian (2001) como evento - e ao gestor cabe articular as possibilidades de ação. 
Le Boterf (2003) é um dos autores que destacam que esse entendimento acerca da competência reside na transposição dos recursos (conhecimentos e capacidades) para o ato. "Não há competência senão posta em ato, a competência só pode ser compreendida em situação" (LE BOTERF, 2003, p.51). Na busca pela compreensão do conceito de competências, este autor ilumina sua decodificação ao descrevê-lo como uma teia com elementos que se entrelaçam, agregando diversos saberes, como saber agir e reagir com pertinência; saber combinar recursos e mobilizar; saber transpor; saber comunicar-se e saber envolver-se. Assim, podem-se perceber estes fios aprofundando o olhar sobre as competências. Percebe-se que ela é mobilizada em um contexto e que não são apenas os conhecimentos que contam, mas, sobretudo, o seu emprego em uma situação de trabalho oportuna, talvez sob estresse e pressão, demandando também a subjetividade da pessoa.

As competências gerenciais podem ser compreendidas como a mobilização dos saberes (saber, saber agir e saber ser) requeridos pelo contexto da ação gerencial (LE BOTERF, 2003; MOURA e BITENCOURT, 2006). A abordagem das competências gerenciais pressupõe um elenco de ações relacionadas à compreensão cognitiva, prática e afetiva de situações de trabalho (BRANDÃO e BORGES-ANDRADE, 2007) para a categoria específica de gestores. A sua expressão no contexto do trabalho deve ser concebida pela "construção de novas formas de pensar e atuar no âmbito gerencial e relacional" (RUAS, 2001, p. 243), visualizada na ação profissional destes gerentes (FLEURY e FLEURY, 2001; LE BOTERF, 2003; RUAS, 2001).

As competências mobilizadas dependem do nível de complexidade na gestão de processos e pessoas vinculadas ao posicionamento econômico da organização no mercado. Assim, as competências solicitadas diferem em relação ao nível de responsabilidade desempenhado pelos gerentes, visto que devem ser validadas (DUTRA, 2004), e, no caso das organizações, legitimadas pelo contexto (ZARIFIAN, 2001).

Ao considerar a expressão das competências no ambiente das instituições federais de ensino superior, percebe-se que a necessidade de profissionalismo na gestão pública, que é uma das diretrizes da área de desenvolvimento de pessoas no serviço público, instrumentalizada por meio do decreto-lei 5.707/06, demanda a necessidade de implantar processos gerenciais que propiciem um melhor desempenho para estas instituições. Portanto, as competências gerenciais são essenciais na condução das mudanças, uma vez que podem contribuir para o desenvolvimento de competências institucionais, possibilitando a melhoria dos resultados sociais das IFES (DUTRA, 2004 ; RUAS, 2001).

Ressalta-se que melhores resultados na gestão pública podem ser atribuídos, entre outros fatores, à viabilidade na articulação entre as competências individuais dos servidores e à estratégia de cada órgão público e na busca do profissionalismo, mas ainda deve percorrer caminhos no avanço das competências gerenciais necessárias aos cargos ocupados pelos seus gestores.

Dessa maneira, é possível aos gestores coordenar o desenvolvimento das competências necessárias aos servidores, o que possibilita a melhoria na qualidade nas práticas de trabalho, na resolução de problemas e no aumento do desempenho, que, no caso específico das IFES, pode ampliar a sua função social por meio da oferta de um serviço de qualidade e também da efetividade no uso dos recursos públicos. O reflexo do desempenho das IFES na sociedade pode ser observado por meio da satisfação ou insatisfação da própria sociedade, isto é, pelo feedback nas relações com a instituição percebidos no ingresso de novos alunos, no credenciamento de cursos e pós-graduações, bem como do financiamento de projetos via Coordenação de Aperfeiçoamento de Pessoal de Nível Superior (CAPES) e Conselho Nacional de Desenvolvimento Científico e Tecnológico (CNPq). Caso esses indicadores sejam favoráveis, repercutem nos seus resultados e contribuem para a criação de uma imagem institucional que pode tornar-se referência em práticas de gestão pública.

A literatura direciona um caminho de aberturas (ao contexto, às mudanças sociais, às necessidades individuais dos trabalhadores e das organizações) e, para estar em sintonia e contemplar tais demandas, o outro trecho deste percurso indica o desenvolvimento gerencial, que envolve aprender na ação, 
experimentar novos processos de gestão e refletir sobre suas atitudes e valores. Amaral (2006), ao contextualizar o perfil identificado nos servidores da ENAP, menciona a necessidade de uma constante análise dos cenários sociais - que são "tradutores culturais" (AMARAL, 2006, p. 560) - e interação com diferentes contextos, além das competências requeridas, como gerenciar com ética pessoas e interesses públicos; inovar processos; construir estratégias eficazes ao avaliar riscos e reconhecer oportunidades e ameaças. Portanto, as organizações públicas buscam um novo perfil alinhado ao ser gestor capaz de mobilizar novas competências face aos desafios das organizações públicas.

\section{Metodologia}

O percurso metodológico em uma pesquisa implica escolhas, recortes da realidade, que ajudam o pesquisador a conhecer melhor seu objeto de estudo. Ao definir a maneira de colher os dados sobre determinado fenômeno, jogam-se as redes, estabelecem-se os contornos e as definições com a intenção de encontrar a "verdade" sobre o questionamento inicial da pesquisa (ALVES, 1992; DEMO, 2008).

Este estudo caracteriza-se como uma pesquisa qualitativa, de natureza exploratória, que busca captar a percepção de um grupo de gestores acerca das competências gerenciais por meio da utilização do focus group como estratégia para coleta de material empírico, caracterizado por entrevistas grupais em profundidade, nas quais os participantes avaliam temas colocados em discussão, de suas perspectivas. Para Vergara (2005, p. 111), o focus group é "um método de coleta de dados que consiste na realização de entrevistas em grupo conduzidas por um moderador. Tem como objetivo a discussão de um tópico específico". Assim, os entrevistados discutem e expressam pensamentos, crenças e sentimentos acerca de suas experiências em uma determinada área. Outros aspectos inerentes ao focus group estão em permitir uma aproximação maior da realidade natural (no caso, o cenário laboral dos gestores) e a interação entre eles (OLIVEIRA e FREITAS, 2006). Esta abordagem possibilitou compreender a relação de significado entre o mundo objetivo e a subjetividade dos sujeitos. Logo, o conteúdo que emerge nas entrevistas em grupo é exploratório. As falas registradas traduzem a experiência de cada gestor acerca das competências gerenciais.

O contexto da pesquisa foi composto por três universidades: Universidade Federal da Paraíba (UFPB), Universidade Federal do Rio Grande do Norte (UFRN) e Universidade Federal de Pernambuco (UFPE). A amostra foi constituída por 21 gestores, profissionais da área de gestão de pessoas, planejamento, contabilidade e finanças. A amostra foi do tipo não probabilístico, intencional e por conveniência, ao considerar os critérios de acesso e proximidade geográfica.

A coleta dos dados ocorreu no contexto de cada instituição pesquisada. No início das atividades, foi realizada uma breve apresentação em Power Point para explicar o objetivo da pesquisa e da técnica do focus group, bem como a introdução ao tema das competências gerenciais. Foram elaboradas quatro questões para discussão formuladas com base na revisão de literatura (BOWDITCH e BUONO, 2002; DECRETO-LEI 5.825/2006; DUTRA, 2004; FLEURY e FLEURY, 2001; LE BOTERF, 2003; RUAS, 2001; ZARIFIAN, 2001). As perguntas objetivaram levar os gestores públicos a refletir e expressar sua opinião sobre as competências desejáveis em sua atuação profissional associadas a dimensões técnicas, sociais, estratégicas e políticas.

A realização das entrevistas ocorreu em salas de reuniões climatizadas, com a presença exclusiva dos participantes e do moderador. As cadeiras foram colocadas em círculo com a presença do moderador em posição central em relação aos participantes. Solicitou-se que os celulares fossem desligados ou colocados no modo silencioso. Foram utilizados equipamentos MP3 para realizar a gravação em áudio.

As entrevistas em grupo foram posteriormente transcritas com o intuito de mapear as competências gerenciais desejadas aos gestores das IFES. O processo de análise compreensiva interpretativa seguiu as orientações de Silva $(2005,2006)$ e levou a identificação de dimensões e categorias de competências, por 
meio dos relatos dos gestores, da identificação da unidade de significados e da interpretação dos significados. $\mathrm{O}$ resultado da análise possibilitou o estabelecimento de quatro blocos de competências: competências cognitivas, competências funcionais, competências comportamentais e competências políticas. Para cada uma destas dimensões, foi elaborado um quadro para exemplificar como ocorreu a identificação das categorias vinculadas às competências. Os resultados do estudo exploratório são apresentados na próxima seção.

\section{Análise Compreensiva Interpretativa dos Resultados}

Com base na análise dos dados que surgiu do focus group, foram identificadas quatro dimensões associadas a competências: competências cognitivas, competências funcionais, competências comportamentais e competências políticas. Os resultados são apresentados por dimensão e, para facilitar a compreensão, foram elaborados quadros temáticos adaptados do modelo proposto por Silva $(2005,2006)$.

A primeira coluna de cada quadro apresenta a categoria associada a uma competência. A segunda coluna indica a unidade de significado baseada na análise dos relatos dos gestores. A terceira coluna apresenta exemplos de relatos dos gestores que participaram do focus group e a última, uma interpretação dos relatos dos gestores na percepção dos autores.

\section{Competências cognitivas}

As competências cognitivas referem-se à mobilização dos conhecimentos na realização do trabalho e às atividades a serem executadas no dia a dia. Podem ser conceituadas como conhecimentos teóricos e empíricos inerentes ao contexto da ação profissional (LE BOTERF, 2003).

\section{Quadro 3}

\section{Competências Cognitivas}

\begin{tabular}{|c|c|c|c|}
\hline \multicolumn{4}{|c|}{ Dimensão: Competências Cognitivas } \\
\hline Categoria & $\begin{array}{l}\text { Unidade de } \\
\text { significado }\end{array}$ & Discurso na linguagem do Gestor & $\begin{array}{c}\text { Interpretação } \\
\text { dos relatos dos Gestores }\end{array}$ \\
\hline Conhecimentos & $\begin{array}{c}\text { Conhecimentos } \\
\text { Teóricos }\end{array}$ & $\begin{array}{l}\text { “Ele tem que ter o conhecimento técnico na } \\
\text { unidade que ele é gestor, conhecer o } \\
\text { processo, porque ele vai ser uma pessoa } \\
\text { facilitadora de todo o trabalho naquela } \\
\text { equipe” (Gestor 5/ UFPB). } \\
\text { “Então eu vejo assim, o conhecimento em si, } \\
\text { como algo assim fundamental na condição e } \\
\text { evolução do gestor ali na área onde ele está } \\
\text { administrando" (Gestor } 3 / \text { UFRN). } \\
\text { "Obviamente conhecer a legislação facilita } \\
\text { bastante, conhecer as demandas das } \\
\text { unidades organizacionais, as demandas }\end{array}$ & $\begin{array}{l}\text { O conhecimento acerca } \\
\text { do trabalho é } \\
\text { fundamental para o êxito } \\
\text { do desempenho dos } \\
\text { gestores na prática } \\
\text { gerencial } \\
\text { Capacidade de } \\
\text { compreender o fluxo de } \\
\text { trabalho na sua unidade } \\
\text { gerencial e da } \\
\text { interconexão com outros }\end{array}$ \\
\hline
\end{tabular}




\begin{tabular}{|c|c|c|c|}
\hline \multirow{4}{*}{ Conhecimentos } & & $\begin{array}{l}\text { internas, as necessidades que são muito } \\
\text { voláteis, mudam dependendo da gestão, } \\
\text { muda de anos, teve o REUNI" (Gestora 3/ } \\
\text { UFPE). }\end{array}$ & $\begin{array}{l}\text { setores e áreas da } \\
\text { universidade, formando } \\
\text { um todo. }\end{array}$ \\
\hline & $\begin{array}{c}\text { Conhecimentos } \\
\text { Práticos }\end{array}$ & $\begin{array}{l}\text { "Eu diria que o meu conhecimento teórico- } \\
\text { prático, é fundamental para o sucesso dos } \\
\text { trabalhos" (Gestor 5/ UFRN). } \\
\text { "Senti falta de conhecimentos sobre como } \\
\text { organizar e sistematizar o trabalho" } \\
\text { (Gestor } 1 \text { / UFPB). }\end{array}$ & $\begin{array}{l}\text { Possuir os } \\
\text { conhecimentos da área } \\
\text { em que atua, } \\
\text { relacionados à formação } \\
\text { mais técnica, empírica, } \\
\text { aliadoa à formação } \\
\text { conceitual. }\end{array}$ \\
\hline & $\begin{array}{l}\text { Conhecimentos } \\
\text { Procedimentais }\end{array}$ & $\begin{array}{l}\text { "Os gestores têm que ter uma visão ampla } \\
\text { de todo o processo operacional" } \\
\text { (Gestor 5/UFPE). } \\
\text { "A gente percebe no dia a dia da gente que } \\
\text { você vai depender de outro gestor que nem } \\
\text { sempre é guiado pela competência técnica" } \\
\text { (Gestor 4/ UFPB). }\end{array}$ & $\begin{array}{l}\text { Perceber a importância } \\
\text { de estar atualizado com } \\
\text { informações relacionadas } \\
\text { aos procedimentos, tais } \\
\text { como legislação, } \\
\text { sistemas em rede, } \\
\text { observar como as } \\
\text { pessoas estão mais } \\
\text { informadas. }\end{array}$ \\
\hline & $\begin{array}{c}\text { Conhecimentos } \\
\text { Contextuais }\end{array}$ & $\begin{array}{l}\text { "Uma coisa importante é acompanhar os } \\
\text { sistemas que vão aparecendo, temos muitos, } \\
\text { tem o MEC, o de patrimônio, tudo em nível } \\
\text { federal" (Gestor } 7 / \text { UFPE). } \\
\text { "Tem que conhecer um pouco de tudo pra } \\
\text { ele poder saber gerenciar e atuar de um } \\
\text { modo geral, em todo o processo e também } \\
\text { ter uma visão da instituição como um todo" } \\
\text { (Gestor 5/UFPB). } \\
\text { "Conhecer a unidade gerenciada com uma } \\
\text { visão holística e ao mesmo tempo bem } \\
\text { específica" (Gestora 1/ UFRN). }\end{array}$ & $\begin{array}{l}\text { Capacidade de } \\
\text { compreender e visualizar } \\
\text { a o contexto da } \\
\text { instituição, fazendo } \\
\text { conexões dos processos } \\
\text { de trabalho com as } \\
\text { estratégias da } \\
\text { organização. }\end{array}$ \\
\hline
\end{tabular}

Fonte: Elaborado pelos autores, 2010.

Os gestores apontam o saber e as especificidades da profissão, destacando o conhecimento como componente determinante ligado não só ao processo, mas também ao contexto da sua ação profissional. $\mathrm{O}$ desenvolvimento de tais competências se configura como um processo educativo, que deve acompanhar o gestor na vida e na profissão, incorporando as transformações ocorridas no mundo do trabalho e na gestão pública (ENAP, 2009; NEWCOMER, 1999; NOGUEIRA, 2005).

O decreto 5.825/06 considera que o conhecimento advindo da realização do trabalho nas universidades seja considerado de domínio público. Logo, no momento em que os profissionais compartilham conhecimentos por meio de uma linguagem, mapas e estruturas mentais similares, amplia-se a possibilidade de melhorar a interação no trabalho. Como parte deste compartilhamento, a necessidade de conexão entre setores da 
organização surge como um imperativo de integração, sendo urgente conhecer o impacto do seu trabalho sobre as outras áreas (BASTOS, 2004 ; ZARIFIAN, 2003).

Outro aspecto refere-se ao papel do contexto mais amplo, seja em nível nacional ou mundial, na gestão das instituições públicas de educação superior, pois o que acontece na economia e na política repercute na esfera do trabalho, causando impacto na gestão, o que torna necessário o desenvolvimento de outra competência entre os gestores.

\section{Competências funcionais}

Reúnem aspectos relacionados à gestão dos processos de trabalho, à complexidade e à definição das estratégias da organização.

A gestão dos processos de trabalho refere-se à forma como as atividades são desenvolvidas para identificar prioridades e demandas, utilizar com eficácia os recursos e definir a estratégia da organização aliada às políticas públicas. Os processos de trabalho também passam a ser considerados fundamentais na atividade dos gestores das IFES e podem ser definidos como um "conjunto de ações sequenciadas que organizam as atividades da força de trabalho e a utilização dos meios de trabalho, visando o cumprimento dos objetivos e metas institucionais" (Art. 3, II, do Decreto 5285/06). Este decreto também destaca que os gestores das IFES precisam apropriar e aprimorar os processos de trabalho, transformando-os em conhecimento coletivo e de domínio público, passando a atuar como sujeitos do planejamento institucional.

O estabelecimento de configurações organizacionais mais favoráveis é uma preocupação dos paísesmembros da OCDE (Organização para a Cooperação e o Desenvolvimento Econômico), como o Brasil (NOGUEIRA, 2005), e perpassa pela administração gerencial e profissionalização dos gestores (SOUZA, 2002).

A complexidade desponta como segunda categoria de análise e permeia as mudanças e instabilidades contemporâneas. Logo, os gestores necessitam ter competência para geri-la, na medida em que a atividade multifacetada destes profissionais lida com fatores objetivos e subjetivos, instáveis, e recebem influências das transformações tecnológicas e do contexto social (SILVA, 2009). Portanto, a instituição de uma cultura favorável a esse novo contexto institucional pode favorecer atitudes adequadas à sua gestão. O Quadro 4 apresenta a categorização das competências funcionais.

Quadro 4

Competências Funcionais

Dimensão: Competências Funcionais

\begin{tabular}{|l|l|l|l|}
\hline Categoria & $\begin{array}{l}\text { Unidade de } \\
\text { significado }\end{array}$ & Discurso na linguagem do Gestor & $\begin{array}{l}\text { Interpretação dos } \\
\text { relatos dos gestores }\end{array}$ \\
\hline $\begin{array}{l}\text { Gerenciamento } \\
\text { de processos de } \\
\text { trabalho }\end{array}$ & $\begin{array}{l}\text { Gestão do } \\
\text { processo de } \\
\text { trabalho }\end{array}$ & $\begin{array}{l}\text { "[...] A análise do trabalho é fundamental, } \\
\text { do que tá acontecendo no dia a dia, a } \\
\text { organização de reuniões para } \\
\text { planejamento e conhecimento da } \\
\text { regulamentação das normas, das leis e } \\
\text { dos processos de trabalho" (Gestora 7/ } \\
\text { UFRN). }\end{array}$ & $\begin{array}{l}\text { Necessidade de } \\
\text { planejamento nos } \\
\text { processos } \\
\text { organizacionais. }\end{array}$ \\
\hline
\end{tabular}




\begin{tabular}{|c|c|c|c|}
\hline $\begin{array}{l}\text { Gerenciamento } \\
\text { da complexidade }\end{array}$ & $\begin{array}{l}\text { Incertezas, } \\
\text { mudanças de } \\
\text { cenário. }\end{array}$ & $\begin{array}{l}\text { “O processo decisório no serviço público, } \\
\text { ele é complexo" (Gestor } 2 / \text { UFPE). } \\
\text { "Em nível de governo federal, você } \\
\text { qualifica o funcionário, ele está } \\
\text { desenvolvendo bem a função dele e, de } \\
\text { repente, ele passa em outro concurso, } \\
\text { porque o MEC não remunera tão bem, e } \\
\text { ele já tá altamente treinado, capacitado. } \\
\text { Isto causa uma rotatividade" (Gestor } \\
\text { 5/UFPE). }\end{array}$ & $\begin{array}{l}\text { Articulação do } \\
\text { ambiente sócio-político } \\
\text { influenciando a gestão } \\
\text { nas IFES. } \\
\text { A percepção do quanto } \\
\text { o trabalho é mutável } \\
\text { depende de recursos, } \\
\text { políticas públicas, novas } \\
\text { legislações. }\end{array}$ \\
\hline $\begin{array}{l}\text { Formulação de } \\
\text { planos e } \\
\text { estratégias }\end{array}$ & $\begin{array}{l}\text { Influência do } \\
\text { macroambi- } \\
\text { ente e do } \\
\text { contexto } \\
\text { sócio-político }\end{array}$ & $\begin{array}{l}\text { "A questão é a mesma: trabalhar com } \\
\text { alternativas, vários cenários, visão de } \\
\text { futuro, as possibilidades que poderiam } \\
\text { acontecer" (Gestora 7/UFRN). } \\
\text { "Ser flexível, estar em permanente } \\
\text { estado de prontidão. Você tem o plano A, } \\
\text { mas tem que visualizar o B, C; se brincar, } \\
\text { o D" (Gestora 3/UFPE). }\end{array}$ & $\begin{array}{l}\text { Nas estratégias, o } \\
\text { gestor deve saber aliar } \\
\text { recursos e capacidades } \\
\text { e, muitas vezes, } \\
\text { esquece os recursos } \\
\text { humanos disponíveis } \\
\text { para realizar aquelas } \\
\text { tarefas. }\end{array}$ \\
\hline
\end{tabular}

Fonte: Elaborado pelos autores, 2010.

O contexto sociopolítico nas organizações públicas é outro componente da complexidade. De acordo com Ring e Perry (1985), o ambiente do setor público é mais sujeito a legislações, normas e especificidades, como os concursos públicos e a interferência da mídia, que impactam as decisões no contexto público. Constata-se que as políticas públicas definidas refletem em constantes alterações nos processos de trabalho dos gestores, seja na adequação a novos procedimentos legais, na implantação de sistemas contábeis ou nas práticas recomendadas para o desenvolvimento de pessoal, que perpassam pelas competências comportamentais, na esfera das instituições de ensino superior.

\section{Competências comportamentais}

As competências comportamentais, de acordo com D'Amelio e Godoy (2009, p. 4), constituem "a habilidade para adotar comportamento apropriado, observável em situações relacionadas ao trabalho, em seu posicionamento diante das atividades e na interação com outros". Referem-se ao setting social por meio do qual as pessoas interagem para realizar suas tarefas profissionais. É o saber ser, possuir atitudes que agreguem, consigam unir, harmonizar, comunicar e fazer com que as atividades sejam executadas bem e sem conflitos.

Nesta dimensão eclodiram quatro categorias vinculadas às competências (saber ouvir, liderança, responsabilidade e interação social).

No saber ouvir, o gestor precisa estar aberto a sugestões, críticas, ideias novas, oxigenando o ambiente, recebendo as contribuições de sua equipe. Já a liderança envolve um processo de influência do gestor para o grupo, objetivando atingir as metas, e, de acordo com Bowditch e Buono (2002), pode ser qualificada como transacional, exercida pela troca de favores, ou transformacional, construída pelo compartilhamento de ideais e convicções. Quando os servidores internalizam novos valores e modificam sua prática pelo exercício desta liderança, a condução da equipe é mais fluida. 
A interação social relaciona-se à gestão de pessoas e surge como uma considerável competência comportamental, representando a articulação do precioso recurso formado pelas pessoas, bem como algo complexo. Grande parte da rotina do gestor envolve a gestão das equipes, a resolução de conflitos, o que o leva a transpor as habilidades conceituais, demandando empatia, flexibilidade e liderança, para uma interação harmoniosa entre ele e sua equipe. Traduz-se na vitalidade e contribui para a sobrevivência e competitividade das organizações, conferindo-lhes valor econômico e social (FLEURY e FLEURY, 2001). Em um contexto dinâmico, torna-se mais difícil gerenciar e conciliar os interesses organizacionais aos pessoais (DUTRA, 2004).

\section{Quadro 5}

\section{Competências comportamentais.}

\begin{tabular}{|c|c|c|c|}
\hline \multicolumn{4}{|c|}{ Dimensão: Competências Comportamentais } \\
\hline Categoria & $\begin{array}{l}\text { Unidade de } \\
\text { significado }\end{array}$ & Discurso na linguagem do Gestor & $\begin{array}{l}\text { Interpretação dos } \\
\text { relatos dos gestores }\end{array}$ \\
\hline Saber Ouvir & $\begin{array}{l}\text { Abertura ao } \\
\text { outro, } \\
\text { escutar } \\
\text { outras } \\
\text { possibili- } \\
\text { dades }\end{array}$ & $\begin{array}{l}\text { "Fundamental é saber ouvir, porque eu } \\
\text { acho que, muitas vezes, por ser gestor a } \\
\text { pessoa acaba se fechando nas suas } \\
\text { conviç̧̃̃es e deixando a riqueza e o } \\
\text { conhecimento da sua equipe" (Gestor } 1 \text { / } \\
\text { UFPB). } \\
\text { “O saber ouvir, saber se colocar no lugar } \\
\text { do outro, mas sem perder de foco a } \\
\text { organização, as metas institucionais. } \\
\text { Empatia, saber delegar" (Gestora } 3 / \\
\text { UFPE). } \\
\text { "Tentar ouvir o dobro do que fala" } \\
\text { (Gestor 2/UFPE). }\end{array}$ & $\begin{array}{l}\text { Capacidade de } \\
\text { interagir com o outro, } \\
\text { escutando opiniões, } \\
\text { sugestões sobre os } \\
\text { processos de trabalho. } \\
\text { Considerar a equipe, } \\
\text { ouvir suas falas. }\end{array}$ \\
\hline Liderança & $\begin{array}{l}\text { Uso da } \\
\text { liderança } \\
\text { como um } \\
\text { atributo do } \\
\text { gestor }\end{array}$ & $\begin{array}{l}\text { "Alguém que tem espírito de liderança, } \\
\text { que consegue trazer as pessoas pro seu } \\
\text { time, sem precisar impor a força, é uma } \\
\text { conquista" (Gestor 4/ UFPB). } \\
\text { "A liderança servidora nos ensina que } \\
\text { você não deve administrar com a caneta, } \\
\text { com a força do cargo, fazendo que os seus } \\
\text { liderados entendam que é uma missão } \\
\text { dele trabalhar pra a instituição, é uma } \\
\text { coisa boa" (Gestor 5/ UFPB). }\end{array}$ & $\begin{array}{l}\text { Conseguir utilizar a } \\
\text { liderança para } \\
\text { gerenciar pessoas, sem } \\
\text { exercer a autoridade, } \\
\text { influenciando o } \\
\text { comportamento, } \\
\text { conduzindo a equipe. }\end{array}$ \\
\hline Responsabilidade & $\begin{array}{l}\text { Atitude } \\
\text { responsável }\end{array}$ & $\begin{array}{l}\text { "Uma competência é essa apropriação, } \\
\text { compreender o seu lugar no exercício da } \\
\text { gestão e da equipe, ele faz parte da } \\
\text { equipe, de um lugar destacado de } \\
\text { responsabilidade" (Gestor 4/ UFRN) }\end{array}$ & $\begin{array}{l}\text { Assumir para si } \\
\text { atribuições, } \\
\text { compromissos, } \\
\text { agendas. Ser executor } \\
\text { de atividades, } \\
\text { assumindo sua autoria. }\end{array}$ \\
\hline
\end{tabular}




\begin{tabular}{|c|c|c|c|}
\hline & & $\begin{array}{l}\text { "Acho que na forma como o gestor } \\
\text { estimula sua equipe, a comunicação vem } \\
\text { no estabelecimento das funções, } \\
\text { responsabilidades, que resultados a } \\
\text { gente quer assumir [...]" (Gestora 1/ } \\
\text { UFRN). }\end{array}$ & \\
\hline Interação social & $\begin{array}{l}\text { Relacionar-se } \\
\text { com equipe, } \\
\text { clientes e } \\
\text { fornecedores }\end{array}$ & $\begin{array}{l}\text { "Se o gestor tiver habilidade de } \\
\text { comunicação e de reconhecimento do } \\
\text { trabalho, eu acho que se consegue ter a } \\
\text { equipe participando, sem impor" (Gestor } \\
\text { 5/UFPB). } \\
\text { "Saber pedir, interagir com o servidor, } \\
\text { para que ele aja não sobre pressão, mas } \\
\text { com o comprometimento e a satisfação } \\
\text { em realizar" [...] (Gestora 1/ UFPE). }\end{array}$ & $\begin{array}{l}\text { Perceber a importância } \\
\text { de saber falar com o } \\
\text { outro, se expressar. } \\
\text { Tornar claro o que } \\
\text { deseja. }\end{array}$ \\
\hline
\end{tabular}

Fonte: Elaborado pelos autores, 2010.

Uma pesquisa realizada por Campos, Sousa, Campos et al. (2008), para identificar as dificuldades dos gestores, constatou que a área de gestão de pessoas é uma das mais complexas e difíceis de lidar, o que é corroborado pelos resultados deste estudo. $\mathrm{O}$ engessamento que os gestores públicos das IFES vivenciam pela falta de mecanismos capazes de beneficiar os servidores mais comprometidos aparece como uma dificuldade, identificada na subcategoria de gerenciar pessoas, como neste discurso: "O servidor não vai ser demitido porque não quis trabalhar [...]" (Gestor 5/ UFPB)

Outro atributo citado foi o agir responsável (FLEUY e FLEURY, 2001; LE BOTERF, 2003). A responsabilidade é inerente à função de gestor, que responde pelas ações da sua unidade, seja nas atividades cotidianas do trabalho ou nos resultados demandados pela instituição, e que deve ser percebido como membro da equipe não apenas nos acertos, mas também nas dificuldades. A dimensão política emerge como uma competência essencial ao gestor público das universidades.

\section{Competências políticas}

Como o gestor mobiliza suas competências em ação? Suas ações expressam seus pensamentos e valores. Desse modo, as competências políticas perpassam pela compreensão dos interesses relacionados aos valores sociais do gestor, suas atitudes frente à instituição como servidor público. O foco é o público, a junção e colaboração entre os setores. Em outras palavras, o foco não é o personalismo, mas a instituição.

A ética foi citada diversas vezes no focus group como a necessidade de internalizar valores éticos e é imperiosa, principalmente para os gestores, que devem estar sempre em defesa da coisa pública, como se vê no relato de um gestor: "Porque você só adquire uma competência social se você trouxer esta questão ética" (Gestora 2/ UFPB).

De acordo com Chanlat (2002), o componente ético deve basear a conduta pública e é guiado por valores permeados pela ética do bem comum, segundo a qual os servidores devem apresentar qualidades necessárias ao exercício da função pública, tais como dedicação, integridade e igualdade de tratamento a todos os cidadãos. 
Agir com base no interesse público apresenta-se como outra competência política essencial, permitindo mobilizar recursos de uma rede (LE BOTERF, 2003). Um dos gestores entrevistados se expressa assim: "Se eu não desenvolvo um processo de aproximação, receptividade, reciprocidade, com aquela unidade [...] na hora que ele fizer uma reunião pra implementar o projeto [...]" (Gestor 4/ UFRN). O gestor se refere à importância da unicidade de valores para viabilizar ações que elejam o interesse público. Esta capacidade é essencial para o bom andamento do trabalho, priorizando a esfera pública. Deste modo, o gestor busca a solução de algo que surge, ou seja, quer deliberar, resolver com celeridade, articular as possíveis alternativas que promovam a melhora das dificuldades, tendo em vista o bem público.

O decreto 5.825/2006, art. $4^{\circ}$, IV, reforça o caráter público ao indicar que se deve primar pela "construção coletiva para as questões institucionais". Os seminários e encontros de discussão promovidos pelas IFES são espaços adequados para encontrar estes caminhos, considerando que as trocas de informações e experiências configuram meios adequados ao estabelecimento de soluções para as organizações participantes, economizando esforços e seguindo trilhas já percorridas com êxito por instituições parceiras, reservando-se as especificidades presentes a cada uma.

Quadro 6

\section{Competências Políticas}

\begin{tabular}{|c|c|c|c|}
\hline \multicolumn{4}{|c|}{ Dimensão: Competências Políticas } \\
\hline Categoria & $\begin{array}{l}\text { Unidade de } \\
\text { significado }\end{array}$ & Discurso na linguagem do Gestor & $\begin{array}{l}\text { Interpretação dos } \\
\text { relatos dos } \\
\text { gestores }\end{array}$ \\
\hline $\begin{array}{c}\text { Articulação } \\
\text { Social }\end{array}$ & $\begin{array}{l}\text { União de } \\
\text { recursos, } \\
\text { pessoas e } \\
\text { processos }\end{array}$ & $\begin{array}{l}\text { "Tem que ter uma capacidade de juntar as coisas, } \\
\text { aproveitar, tanto no abstrato como no concreto, as } \\
\text { ideias, uma fundamentação legal que você precisa } \\
\text { pra resolver um processo, um argumento bom pra } \\
\text { convencer alguém" (Gestor 4/ UFRN). } \\
\text { "É a questão do bom relacionamento, de fazer } \\
\text { política na instituição, conseguir articular bem as } \\
\text { pessoas, os fornecedores, sejam eles internos ou } \\
\text { externo,.para que a tua atividade, ela possa fluir } \\
\text { bem" (Gestor 1/ UFPB). }\end{array}$ & $\begin{array}{l}\text { Perceber soluções } \\
\text { através da junção } \\
\text { de partes dentro } \\
\text { da instituição. } \\
\text { Usar a } \\
\text { criatividade. } \\
\text { Elaborar soluções } \\
\text { que não estão } \\
\text { prontas. }\end{array}$ \\
\hline Ética & $\begin{array}{c}\text { Postura } \\
\text { adequada e } \\
\text { íntegra }\end{array}$ & $\begin{array}{l}\text { "Eu vejo a questão das competências sociais muito } \\
\text { ligadas à ética... ir assimilando novas culturas com } \\
\text { seus colegas, e esta aprendizagem passa pela questão } \\
\text { ética, aos valores natos ou adquiridos, no decorrer do } \\
\text { seu processo educativo" (Gestora 2/ UFPB). } \\
\text { "O gestor deve ter esta preocupação, porque a coisa } \\
\text { pública não é dele, é do cidadão que paga os } \\
\text { impostos, compreensão que estou gerindo, servindo } \\
\text { a uma coletividade que espera uma resposta sua" } \\
\text { (Gestora 3/ UFPE). }\end{array}$ & $\begin{array}{l}\text { Reconhecimento } \\
\text { de atitudes } \\
\text { relacionadas a } \\
\text { valores } \\
\text { socialmente } \\
\text { aceitos como } \\
\text { corretos. }\end{array}$ \\
\hline
\end{tabular}

Fonte: Elaborado pelos autores, 2010. 
A manutenção da prioridade no âmbito público sobre o privado foi eleita com grande ênfase nesta categoria, na qual o interesse público torna-se relevante. De acordo com o Código de Ética, cap. I, inciso II, "O servidor público não poderá jamais desprezar o elemento ético de sua conduta. Assim, não terá que decidir somente entre o legal e o ilegal, o justo e o injusto, o conveniente e o inconveniente, o oportuno e o inoportuno, mas principalmente entre o honesto e o desonesto, consoante as regras contidas no art. 37, caput, e $\S 4^{\circ}$, da Constituição Federal".

Este cenário probo e ético com sobreposição do público ao privado tem se enfraquecido nas instituições governamentais e uma revitalização na cultura pode ajudar a reverter esta tendência, por meio da disseminação de valores adequados ao exercício dos gestores e servidores.

\section{Considerações Finais}

O contexto das instituições públicas passa por um processo de transformação, demandando a necessidade de profissionalismo e desenvolvimento de gestores públicos com competências para enfrentar as situações profissionais complexas que permeiam a gestão pública. Percebe-se que a sociedade cultiva uma postura mais ativa e exige celeridade e qualidade na prestação dos serviços governamentais.

A gestão de pessoas nas Instituições Federais de Educação Superior passa por transformações decorrentes de um conjunto de leis e decretos que suscitam uma nova visão de gestão de pessoas, mais profissionalizada e alinhada as diretrizes institucionais. Nenhuma mudança será viabilizada se os gestores públicos não forem preparados para esse novo contexto institucional.

Este estudo piloto teve como objetivo identificar as competências dos gestores públicos que atuam nas IFES segundo a percepção de gestores de três instituições: UFPE, UFPB e UFRN. As competências gerenciais resultantes do estudo são descritas no Quadro 7.

Quadro 7

\section{Competências gerenciais nas IFES}

\begin{tabular}{|c|c|l|}
\hline Dimensão & Categoria & \multicolumn{1}{c|}{ Competência Gerencial } \\
\hline \multirow{6}{*}{$\begin{array}{c}\text { Conhecimentos } \\
\text { técnicos }\end{array}$} & $\begin{array}{l}\text { Executar as atividades profissionais utilizando um conjunto de } \\
\text { procedimentos técnicos e legais para o aprimoramento do } \\
\text { trabalho na instituição. }\end{array}$ \\
\cline { 2 - 3 } & $\begin{array}{c}\text { Conhecimento do } \\
\text { ambiente } \\
\text { institucional }\end{array}$ & $\begin{array}{l}\text { Identificar aspectos sociais, econômicos e políticos do } \\
\text { ambiente institucional na tomada de decisão. }\end{array}$ \\
\cline { 2 - 4 } & $\begin{array}{c}\text { Desenvolvimento } \\
\text { do servidor }\end{array}$ & $\begin{array}{l}\text { Elaborar, em parceria com o servidor, ações que proporcionem } \\
\text { o seu desenvolvimento profissional alinhado às estratégias } \\
\text { institucionais. }\end{array}$ \\
\cline { 2 - 4 } & $\begin{array}{c}\text { Conhecimentos } \\
\text { operacionais }\end{array}$ & $\begin{array}{l}\text { Realizar atividades vinculadas ao ambiente de atuação } \\
\text { profissional que proporcionem qualidade e agilidade aos } \\
\text { serviços prestados à comunidade. }\end{array}$ \\
\hline
\end{tabular}




\begin{tabular}{|c|c|c|}
\hline \multirow{2}{*}{$\begin{array}{l}\text { Competências } \\
\text { Funcionais }\end{array}$} & $\begin{array}{l}\text { Orientação } \\
\text { estratégica }\end{array}$ & $\begin{array}{l}\text { Elaborar estratégias valendo-se da análise do contexto } \\
\text { institucional, vinculando-as às diretrizes da Instituição Federal } \\
\text { de Ensino em que o gestor trabalha. }\end{array}$ \\
\hline & $\begin{array}{l}\text { Processos de } \\
\text { trabalho }\end{array}$ & $\begin{array}{l}\text { Assumir a responsabilidade pelas decisões relacionadas aos } \\
\text { processos de trabalho, avaliando as suas consequências. }\end{array}$ \\
\hline \multirow{8}{*}{$\begin{array}{l}\text { Competências } \\
\text { Comportamentais }\end{array}$} & $\begin{array}{l}\text { Senso de } \\
\text { responsabilidade }\end{array}$ & $\begin{array}{l}\text { Mobilizar atitudes como responsabilidade e autonomia no } \\
\text { gerenciamento das mudanças ocorridas no ambiente de } \\
\text { trabalho. }\end{array}$ \\
\hline & Empatia & $\begin{array}{l}\text { Reconhecer com clareza os sentimentos e valores presentes na } \\
\text { equipe de trabalho, demonstrando interesse e respeito pelo } \\
\text { outro. }\end{array}$ \\
\hline & $\begin{array}{l}\text { Gerenciamento } \\
\text { de conflitos }\end{array}$ & $\begin{array}{l}\text { Gerenciar as dificuldades interpessoais e conflitos vivenciados } \\
\text { na equipe. }\end{array}$ \\
\hline & Interação social & $\begin{array}{l}\text { Estabelecer relações de trabalho com a equipe pautadas em } \\
\text { valores como igualdade, reciprocidade e imparcialidade. }\end{array}$ \\
\hline & Liderança & $\begin{array}{l}\text { Promover ações que influenciem positivamente o } \\
\text { comportamento das pessoas na geração de ideias e no } \\
\text { estabelecimento de diretrizes no contexto da ação } \\
\text { profissional. }\end{array}$ \\
\hline & Saber ouvir & $\begin{array}{l}\text { Estimular os integrantes da equipe a contribuir com sugestões } \\
\text { e críticas relacionadas aos processos de trabalho. }\end{array}$ \\
\hline & $\begin{array}{l}\text { Equilíbrio } \\
\text { emocional }\end{array}$ & $\begin{array}{l}\text { Manter o equilíbrio emocional diante das pressões do } \\
\text { ambiente de trabalho durante a realização das atividades. }\end{array}$ \\
\hline & Comunicação & $\begin{array}{l}\text { Utilizar a comunicação de forma compreensível, por meio da } \\
\text { linguagem oral e escrita, como facilitadora do trabalho em } \\
\text { equipe. }\end{array}$ \\
\hline \multirow{3}{*}{$\begin{array}{l}\text { Competências } \\
\text { Políticas }\end{array}$} & Ética & $\begin{array}{l}\text { Praticar os valores e princípios presentes no código de ética do } \\
\text { servidor público. }\end{array}$ \\
\hline & Interesse público & $\begin{array}{l}\text { Estimular a defesa dos interesses institucionais, utilizando os } \\
\text { bens públicos em benefício da sociedade. }\end{array}$ \\
\hline & $\begin{array}{l}\text { Parcerias } \\
\text { cooperativas }\end{array}$ & $\begin{array}{l}\text { Estabelecer parcerias cooperativas com setores internos, } \\
\text { órgãos externos e outras instituições federais de ensino, } \\
\text { visando à construção coletiva de soluções para as dificuldades } \\
\text { institucionais. }\end{array}$ \\
\hline
\end{tabular}

Fonte: Elaborado pelos autores, 2010. 
As competências identificadas podem contribuir para a formação de gestores públicos alinhados ao contexto institucional. Nesse sentido, destaca-se a necessidade de se aprofundar a análise das competências gerenciais identificadas por meio de um estudo quantitativo com gestores de várias instituições, visando a validar uma escala de competências gerenciais nas IFES.

\section{Referências}

ALVES, R. Filosofia da ciência: introdução ao jogo e suas regras. 15. ed. São Paulo: Editora Brasiliense, 1992.

AMARAL, H. K. Desenvolvimento de competências de servidores na administração pública brasileira. Revista do Serviço Público Brasília, 57 (4), p. 549-563, out./dez. 2006.

ANDRADE, P. R. Bem-estar psicológico de servidores e funcionários técnico-administrativos de Institutos de ensino superior: indicadores e antecedentes. 2008. Tese (Doutorado em Psicologia) - Programa Integrado de Pósgraduação em Psicologia Social na UFRN/UFPB, Natal, 2008.

ANTUNES, R. Os sentidos do trabalho: ensaios sobre a afirmação e a negação do trabalho. 3 ed. São Paulo: Boitempo, 2000.

BASTOS, A. V. B. et al. Conceito e perspectivas de estudo nas organizações. In: ZANELLI, J. C.; BORGESANDRADE, J. E; BASTOS, A. V. B. Psicologia, organizações e trabalho no Brasil. Porto Alegre: Artmed, 2004. Cap.2, p. 24-62.

BITENCOURT, C. C.; APPLE, H. Gestão de pessoas por competência: institucionalização, possibilidades e dificuldades implícitas nas relações trabalhistas brasileiras. ENANPAD, XXIX, 2005, Brasília/DF. CD-ROM.

BITENCOURT, C. C; BARBOSA, A. C. Q. Gestão de competências: articulando indivíduos, organizações e sociedade. In: BITENCOURT, C. C. (Org.) A Gestão contemporânea de pessoas: novas práticas, conceitos tradicionais. Porto Alegre: Bookman, 2004. Cap. 10, p. 176-195.

BORGES, A. M. C. Reforma do estado, emprego público e a precarização do mercado de trabalho. Caderno CRH, Salvador, v. 17, n. 41, p. 255-268, maio/ago., 2004.

BOWDITCH, J. L.; BUONO, A. F. Elementos do comportamento organizacional. São Paulo: Pioneira, 2002. Cap. 7 , p. 117-141.

BRANDÃO, H. P.; BORGES-ANDRADE, J. E. Causas e efeitos da expressão de competências no trabalho: para entender melhor a noção de competência. Revista de Administração Mackenzie/ RAM, v. 8, n. 3, p. 32-49, 2007.

BRASIL. Ministério da Administração Federal e da Reforma do Estado. Plano diretor da reforma do aparelho do Estado. Brasília. Presidência da República, 1995. Disponível em: <http://www.bresserpereira.org.br/Documents/MARE/PlanoDiretor/planodiretor.pdf.> Acesso em: 24/03/2010.

. Presidência da República. Lei 11.091 (PCCTAE), de 12 de janeiro de 2005. Dispõe sobre a estruturação do Plano de Carreira dos Cargos Técnico-Administrativos em Educação, no âmbito das Instituições Federais de Ensino vinculadas ao Ministério da Educação, e dá outras providências. Disponível em: <http://www.planalto.gov.br/ccivil03/_Ato2004-2006/2005/Lei/L11091.htm>. Acesso em: 04/01/10.

Decreto-Lei 5.707, de 23 de fevereiro de 2006. Institui a Política e as Diretrizes para o Desenvolvimento de Pessoal da administração pública federal direta, autárquica e fundacional, e regulamenta dispositivos da Lei no 8.112, de 11 de dezembro de 1990. Disponível em: <http://www.planalto.gov.br/ccivil/ Ato20042006/2006/Decreto/D5707.htm >. Acesso em: 04/01/10. 
Decreto-Lei 5.824, de 29 de junho de 2006. Estabelece os procedimentos para a concessão do Incentivo à Qualificação e para a efetivação do enquadramento por nível de capacitação dos servidores integrantes do Plano de Carreira dos Cargos Técnico-Administrativos em Educação, instituído pela Lei no 11.091, de 12 de janeiro de 2005. Disponívelem:<http://www.planalto.gov.br/ccivil_03/_Ato20042006/2006/Decreto/D5824.htm>. Acesso em: 04/01/10.

Decreto-Lei 5.825, de 29 de junho de 2006. Estabelece as diretrizes para elaboração do Plano de Desenvolvimento dos Integrantes do Plano de Carreira dos Cargos Técnico-Administrativos em Educação, instituído pela Lei no 11.091, de 12 de janeiro de 2005. Disponível em: <http://www.planalto.gov.br/CCIVIL/_Ato20042006/2006/Decreto/D5825.htm>. Acesso em: 04/01/10.

CAMPOS, D. C. S.; SOUSA, N.B.; CAMPOS, A.B.; CUNHA, N.R.S.; MAGALHÃES, E.M.; CARVALHO, R.M.M.A. Competências Gerenciais Necessárias aos Professores-Gerentes que Atuam em Pró-Reitorias: o caso de uma Instituição Federal de Ensino Superior de Minas Gerais. ENANPAD, XXXII, 2008, Rio de Janeiro- RJ. CD-ROM.

CHANLAT, J. F. Mitos e realidades sobre o estresse de gerentes. In: DAVEL, E. MELO, M.C.O.L. (Orgs.) Gerência em Ação: singularidades e dilemas do trabalho gerencial, Rio de Janeiro: FGV, 2005, p. 29-65.

COSTA, M. S. O sistema de relações de trabalho no Brasil: alguns traços históricos e sua precarização atual. Revista Brasileira de Ciências Sociais, v. 20, n. 59, out. 2005.

D’AMELIO, M.; GODOY, A. S. Competências gerenciais: a trajetória de construção entre gerentes do setor de saneamento. ENANPAD, XXXIII, 2009. São Paulo/SP. CD-ROM.

DEMO, P. Metodologia do conhecimento científico. São Paulo: Atlas, 2000.

DUTRA, J. S. Competências: conceitos e instrumentos para a gestão de pessoas na empresa moderna. São Paulo: Atlas, 2004.

ESCOLA NACIONAL DE ADMINISTRAÇÃO PÚBLICA. Escolas de governo e gestão por competência: mesaredonda de pesquisa-ação. Brasília: ENAP, 2009.

FÁVERO, M. L. A. A universidade do Brasil: das origens à construção. Rio de Janeiro: Ed. UFRJ, 2000.

A Universidade no Brasil: das origens à Reforma Universitária de 1968. Educar, Curitiba, n. 28, p. 17-36, 2006.

FLEURY, A.; FLEURY, M. T. L. Construindo o conceito de competências. Revista de Administração Contemporânea, Edição Especial, Rio de Janeiro, p. 183-196, 2001.

HARVEY, D. Condição pós-moderna. 9. ed. São Paulo: Edições Loyola, 2000.

LE BOTERF, G. Desenvolvendo a competência dos profissionais. 3. ed. Porto Alegre: Artmed, 2003.

McGILL, I.; BROCKBANK, A. The action learning handbook. New York: Routledge, 2004, Cap. 1, p. 11-25; Cap. 6, p. 91-106, 2004

MEGGINSON, L. C.; MOSLEY, D.C.; PIETRI JR., P. H. Administração: conceitos e aplicações. 4. ed. São Paulo: Harbra, 1998.

MOURA, M. C. C. de; BITENCOURT, C. C. A articulação entre estratégia e o desenvolvimento de competências gerenciais. RAE - eletrônica, v. 5, n. 1, Art. 3, jan./jun. 2006. Disponível em: http://www.rae.com.br/ . Acesso em: 27 fev. 2010.

NEWCOMER, K. A preparação de gerentes públicos para o século XXI. Revista do Serviço Público, Brasília, v. 50 , n. 2, p. 5-18, abr./jun. 1999. 
NOGUEIRA, R. P. Novas tendências internacionais da força de trabalho do setor público: o brasil comparado com outros países. Observatório de Recursos Humanos em Saúde (NESP/CEAM/UnB), 2005. Disponível em: http://www.observarh.org.br/nesc . Acesso em 10 maio 2010.

OLIVEIRA, M.; FREITAS, H. Focus group: instrumentalizando o seu planejamento. In: GODOI, C. K.; MELLO, R. B.; SILVA. A. B. (Orgs.). Pesquisa qualitativa em estudos organizacionais: paradigmas, estratégias e métodos. São Paulo: Saraiva, 2006. p. 325-346.

ORMOND, D.; LÖFFLER, E. A nova gerência pública. Revista do Serviço Público Brasília, v. 50, n. 2, p. 66-96, abr./jun. 1999.

PENENGO, M. O papel do gerente público no processo de mudança. Revista do Serviço Público, Rio de Janeiro, Ano 48, n. 1, p. 81-88, jan./abr., 1997.

RING, P. S.; PERRY, J. L. Strategic management in public and private organizations: implications of distinctive contexts and constraints. The Academy of Management Review, v. 10, n. 2, p. 276-286, 1985.

RUAS, R. Desenvolvendo competências gerenciais e contribuição da aprendizagem organizacional. In: FLEURY, M. T. L.; OLIVEIRA JR. M. M. (Orgs.). Gestão estratégica do conhecimento: integrando aprendizagem, conhecimento e competências. São Paulo: Atlas, 2001. Cap. 8, p. 242-267.

SENGE, P. A Quinta disciplina. São Paulo: Editora Best Seller, 1990.

SILVA, A.B. A vivência de conflitos entre a prática gerencial e as relações em família. 2005. Tese (Doutorado em Engenharia de Produção) - Programa de Pós-Graduação em Engenharia de Produção da Universidade Federal de Santa Catarina, UFSC, Florianópolis, 2005.

A fenomenologia como método de pesquisa em estudos organizacionais. In: GODOI, C. K. ; MELLO, R.B.; SILVA. A. B. (Orgs.). Pesquisa qualitativa em estudos organizacionais: paradigmas, estratégias e métodos. São Paulo: Saraiva, 2006. v. 1, p. 277-307.

Como os gerentes aprendem? São Paulo: Saraiva 2009.

SINAES. Sistema Nacional da Avaliação da Educação Superior: da concepção à regulamentação. 4. ed. ampl. Brasília: Instituto Nacional de Estudos e Pesquisas Educacionais Anísio Teixeira, 2007.

SOUZA, E. C. L. A capacitação administrativa e a formação de gestores governamentais. Revista de Administração Pública, Rio de Janeiro, v. 36, n. 1, p. 73-88, jan./fev. 2002.

VERGARA, S. C. Métodos de pesquisa em administração. São Paulo: Atlas, 2005.

ZARIFIAN, P. Objetivo Competência: por uma nova lógica. São Paulo: Atlas, 2001. 